\title{
Influence of chemical coating combined with nanopatterning on alginate fouling during nanofiltration
}

\author{
Steven T. Weinman and Scott M. Husson* \\ Department of Chemical and Biomolecular Engineering, Clemson University, Clemson, SC
} 29634, USA

\begin{abstract}
*Corresponding author: Tel: +1 (864)-656-4502, Fax: +1 (864)-656-0784. Email address: shusson@clemson.edu
\end{abstract}

\begin{abstract}
This contribution describes a method to increase the fouling resistance of nanofiltration membranes by applying both a chemical coating and a nanoscale pattern to the membrane surfaces. A line and groove nano-pattern was applied by thermal embossing directly onto a commercial polyamide thin-film composite nanofiltration membrane. Poly(ethylene glycol) diglycidyl ether (PEGDE) was reacted onto the patterned membrane surfaces by an epoxide ring opening reaction with unreacted carboxyl groups on the polyamide selective layer. Membrane performance was evaluated by measuring flux and salt rejection using a magnesium sulfate solution and by measuring flux reduction using an alginate solution. Surface characterization showed successful patterning and chemical modification of the membrane surface. Flux and salt rejection properties were unaffected by patterning the polyamide membrane surface directly. The fouling results show that combining line and groove nano-patterning with PEGDE chemical modification yields a membrane that is more resistant to fouling than either method alone.
\end{abstract}




\section{Keywords:}

Biofouling, Surface chemistry, Surface patterning, Thin-film composite membrane

\section{Introduction}

Membrane biofouling refers to the attachment or adsorption of biopolymers or organisms onto the membrane surface or within the membrane pores. It is a major hindrance to membrane usage $[1,2]$, causing a transient flux decline or pressure increase and a decrease in salt rejection. Fouled membranes require chemical cleaning, which shortens the membrane life and greatly increases membrane operating cost [3]. Biofouling is one of multiple steps in the process that leads to biofilm formation [4]. In this process, a conditioning film is adsorbed to the surface, typically comprising macromolecules from the solution or macromolecules secreted from bacteria. This conditioning of the surface provides favorable conditions for bacteria to adsorb or attach onto the surface, where they grow and form colonies, eventually leading to a biofilm.

Biofouling reduction/elimination has been a common topic in the literature. Specifically, surface modification of membranes is a common strategy [5], with numerous studies describing the use of chemical treatments and coatings. Anti-fouling coatings are designed to make the membrane surface less favorable for bacterial attachment; e.g., by making the surface more hydrophilic, by including hydrogen-bond acceptors, by excluding hydrogen-bond donors, and by having an overall neutral electrical charge $[6,7]$. Examples of widely studied antifouling coatings include poly(ethylene glycol) (PEG) due to its high degree of hydration [8, 9], and zwitterions, which are net charge neutral molecules that have positive and negative charge groups that can form a strong hydration layer that excludes biopolymers and bacteria [10]. Three 
zwitterions of interest are carboxybetaine [11], sulfobetaine [12], and phosphobetaine [13], with sulfobetaine being the most commonly used in the literature.

Another common strategy involves coating membranes with anti-microbial agents that are able to kill bacteria. Coatings with quaternary amine groups are common and are thought to disrupt the cell membrane allowing release of intracellular contents causing cell death $[14,15]$. Graphene oxide and carbon nanotubes have shown promise by deactivating bacteria upon contact with these surfaces $[16,17]$. Also, silver nanoparticles have been incorporated into membranes, making anti-microbial membranes that severely damage the bacteria cell membrane $[18,19]$.

A more recent area of interest has been physical modification of surfaces with a specific, ordered pattern to disrupt the hydrodynamic boundary layer at the surface, making foulants less likely to adhere. One of the first designs, coined Sharklet ${ }^{\text {TM }}$ [20-22], used micron-scale patterns that mimic shark skin. Other groups have placed micro-patterned posts [23] and an imprinted spacer design [24] on membrane surfaces in an attempt to reduce biofouling. Micro-patterned hollow fibers also have been of interest with patterning on the outer skin of the hollow fiber to reduce fouling [25-27]. Other micro-patterns applied onto membranes to reduce fouling include line and groove patterns [28], pyramids [29], and prisms [30]. Nano-scale line and groove patterns have been applied onto membranes to reduce protein fouling [31], colloidal particle fouling [32, 33], and gypsum scaling [34].

This paper contributes a method for applying both a chemical coating and a nano-pattern to a membrane surface. First, a nano-scale line and groove pattern was applied to a polyamide thin-film composite membrane by thermal embossing. Next, poly(ethylene glycol) diglycidyl ether (PEGDE) was reacted onto the membrane as a PEG-based chemical coating. The membranes were tested for flux and salt rejection pre- and post-modification in a cross-flow 
system. Alginate was used as a model biopolymer foulant material [35]. To the authors'

knowledge, this paper is the first to report combined chemical and physical modification of a membrane surface to study biofouling resistance, but not the first time these two methods have been combined on a surface [36]. It also is the first to demonstrate the successful, direct thermal embossing of a nano-pattern onto a polyamide thin-film composite membrane.

\section{Materials and methods}

\subsection{Materials}

PEGDE $\left(\mathrm{M}_{\mathrm{n}}=500 \mathrm{Da}\right)$, sodium chloride $(\mathrm{NaCl}, \geq 99 \%)$, magnesium sulfate $\left(\mathrm{MgSO}_{4}, \geq\right.$ 99.5\%), and sodium alginate (from brown algae) were used as received from Sigma Aldrich. Calcium chloride dihydrate $\left(\mathrm{CaCl}_{2} \cdot 2 \mathrm{H}_{2} \mathrm{O}\right)$ was used as received from Fisher Scientific. Aqueous solutions were made with deionized water from a Milli-Q water purification system (EMD Millipore).

Polyamide thin-film composite nanofiltration (NF) membranes (GE HL series) were purchased from Sterlitech Corporation. This membrane consists of a polyester fabric backing, a polysulfone support layer, and a semi-aromatic polyamide selective layer [37].

\subsection{Membrane surface modification}

\subsubsection{Patterning the membrane}

Figure 1 illustrates the two step process of patterning the membrane and applying a chemical coating to the membrane surface. The silicon line and groove stamps used to pattern the membranes were purchased from LightSmyth Technologies, Inc. The stamps were specified to have a $606 \mathrm{~nm}$ period between peaks, a $190 \mathrm{~nm}$ groove depth, and a $303 \mathrm{~nm}$ line width. A $29 \mathrm{~mm}$ 
$\times 12 \mathrm{~mm}$ stamp was used to prepare membranes for physiochemical characterization and salt rejection experiments. A $29 \mathrm{~mm} \times 24 \mathrm{~mm}$ stamp was used to prepare membranes for the alginate fouling experiments. A Carver press (AutoFour/1512H model) was used to emboss the membranes with the stamp/wafer. First, the press plates were heated to $45^{\circ} \mathrm{C}$. A small aluminum plate was placed on the bottom press plate, the membrane was placed on top of the aluminum plate with polyamide surface facing up, and then the silicon stamp was placed on top of the polyamide surface with the stamp features facing the polyamide surface. A $30 \mathrm{~cm} \times 30 \mathrm{~cm}$ Kimwipe was folded into $1 / 16^{\text {th }}$ its original size and placed on top of the stamp to act as a "cushion" to help prevent the stamp from breaking. Another small aluminum plate was placed on top of the Kimwipe. The press plates were closed at $25 \%$ pump speed until the force was $6670 \mathrm{~N}$. A force was maintained at $6670 \pm 1330 \mathrm{~N}$, which was found to be sufficient for patterning without damaging the silicon stamps. After 20 min, the press was released and the stamp was removed from the membrane, leaving a patterned membrane surface.

Control experiments were done to study the effect of the thermal compression alone. For the control process, a $29 \mathrm{~mm} \times 10 \mathrm{~mm}$ flat silicon wafer from Nova Electronic Materials was used to prepare membranes for physiochemical characterization and salt rejection experiments. A $29 \mathrm{~mm} \times 24 \mathrm{~mm}$ flat wafer was used to prepare membranes for the alginate fouling experiments.

\subsubsection{Chemically coating the membrane}

PEGDE was used to modify the membrane surface chemically. Aqueous solutions of 5 wt $\%$ and $15 \mathrm{wt} \%$ PEGDE were used. A control experiment was done using DI water. The reaction process followed that given by Van Wagner et al. [9] with minor modifications. Aluminum foil tape was placed on the membrane edges to create a solution boundary. Next, the 
reaction solution was heated to $42 \pm 2^{\circ} \mathrm{C}$ by a hot plate and approximately $0.2 \mathrm{~g} / \mathrm{cm}^{2}$ membrane of solution was pipetted onto the membrane such that the whole membrane surface area was contacted by the solution. The solution was allowed to react on the membrane for $10 \mathrm{~min}$, and then the membrane was rinsed in DI water. The membranes used for the cross-flow filtration experiments were stored in DI water until use. The membranes used for physicochemical characterization were patted dry and then dried fully under vacuum at $20-25^{\circ} \mathrm{C}$ and $0.78-0.95$ barg. In all cases, the entirety of the membrane testable area was modified with the desired reaction solution.

\subsection{Membrane characterization techniques}

\subsubsection{Atomic Force Microscopy}

Atomic force microscopy (AFM) was used to observe the surface morphology of the stamps and the membranes. Images were obtained using a Bioscope AFM (Bruker, Inc.) with NanoScope IIIa controller equipped with Nanoscope version 5.32R1 software. Silicon cantilevers (MikroMasch, Inc., HQ:NSC16/AL BS) were used as probes for the non-contact tapping mode measurements. AFM images were taken with a $256 \times 256$ pixel resolution over 20 $\mu \mathrm{m} \times 20 \mu \mathrm{m}$ or $5 \mu \mathrm{m} \times 5 \mu \mathrm{m}$ areas at a scan rate of $0.5 \mathrm{~Hz}$. The section analysis feature of the software was used to determine peak heights and peak periods (peak-to-peak distances).

\subsubsection{Laser Measuring Microscopy}

An Olympus LEXT OLS4000 3D laser measuring microscope (software version 2.2.3) was used to take images of the stamps and the patterned membrane surfaces on a larger scale than the AFM. Images were taken with 50x and 100x objective lenses at varying optical zooms 
$(1 \mathrm{x}-8 \mathrm{x})$. Surface roughness measurements were attained using the 50x objective with a $4 \mathrm{x}$ optical zoom ( $\sim 0.004 \mathrm{~mm}^{2}$ area). Surface roughness data were obtained as the root mean square (RMS) height of the surface.

\subsubsection{ATR-FTIR}

Attenuated total reflectance Fourier-transform infrared spectroscopy (ATR-FTIR) was used to characterize the surface chemistry of the pristine and chemically modified membranes. These measurements were done to detect that PEDGE had been grafted onto the membrane surface. Spectra were obtained using a Thermo Scientific Nicolet Nexus 870 FTIR ESP with a zinc sulfide ATR crystal. Data were processed by OMNIC 8.3.103 software (Thermo Scientific). Each spectrum was collected at 128 scans at a resolution of $4 \mathrm{~cm}^{-1}$, corrected with the ATR correction on software, and manually baseline corrected. A background was taken before each set of samples was tested.

\subsection{Membrane performance testing}

A custom cross-flow cell was manufactured by Clemson Machining and Technical Services for all membrane performance testing. An AutoCAD schematic of the cell is presented in the supporting information (Figure S1). The test cell was made from acrylic and can withstand pressures up to 27.6 bar. The membrane testable area was $5.6 \mathrm{~cm}^{2}$. The test solution was pumped from a feed tank to the test cell using a Giant Industries pump head (model 217A-5100 from Southern Municipal Equipment Co., Inc.) and a Marathon Electric pump motor (model E2001A from Motion Industries Inc.). The solution temperature was controlled by use of a Polyscience MM7 chiller (Grainger Industrial Supply) equipped with a homemade stainless steel coil. The 
back pressure was controlled by a gate valve and measured by a stainless steel pressure gauge (3702K44, McMaster-Carr Supply Company), and the concentrate flow rate was measured using an acrylic in-line flow meter (EW-32477-08, Cole Parmer). The permeate flow was collected on an Ohaus ${ }^{\circledR}$ Adventurer ${ }^{\circledR} \mathrm{AX}$ precision balance (VWR International) and not recycled to the feed tank.

\subsubsection{Solution flux and salt rejection}

A $2000 \mathrm{ppm} \mathrm{MgSO}_{4}$ test solution was used to evaluate the integrity of the membrane selective layer after patterning and/or chemical coating. The applied pressure was 8.6 barg and permeate was allowed to flow for 25 min before sample collection. The solution temperature was $22-23^{\circ} \mathrm{C}$ and the cross-flow velocity was $3.0 \pm 0.2 \mathrm{~m} / \mathrm{s}$. A high cross-flow velocity was used to reduce concentration polarization. For patterned membranes, the flow angle was $0^{\circ}$ relative to the line pattern, meaning that solution flow was parallel to the pattern lines. Sixty-two percent of the testable membrane area was patterned. The permeate flow was collected for $4 \mathrm{~min}$ and analyzed for flux and salt rejection measurements. A conductivity meter (Oakton CON 6+, Cole Parmer) was used to measure feed and permeate salt concentrations. The conductivity meter was calibrated by an ICP-OES (Optima 3100RL with autosampler, Perkin Elmer).

\subsubsection{Sodium alginate fouling}

Sodium alginate was used as a model biopolymer for fouling studies. A solution of 30 $\mathrm{mg} / \mathrm{L}$ sodium alginate, $10 \mathrm{mM} \mathrm{NaCl}$ (585 ppm), and $1 \mathrm{mM} \mathrm{CaCl}_{2}$ (111 ppm) was used. Calcium ions were included in the feed solution because they cause alginate to gel, which can lead to an increase in the rate of fouling [38]. The solution temperature was $22-23^{\circ} \mathrm{C}$ and the cross-flow 
velocity was $1.0 \pm 0.1 \mathrm{~m} / \mathrm{s}$. For patterned membranes, the flow angle was $90^{\circ}$ relative to the line pattern. A $90^{\circ}$ flow angle has been shown to reduce fouling due to vortices created at the membrane surface from the patterns [33, 39]. Sixty-eight percent of the testable membrane area was patterned. The approximate desired initial starting flux for each membrane tested was 120 $\mathrm{L} / \mathrm{m}^{2} / \mathrm{h}$. Permeate was collected for approximately 1 min every $5 \mathrm{~min}$ for a total time of $2 \mathrm{~h}$.

\section{Results and discussion}

\subsection{Membrane surface modification}

\subsubsection{Membrane patterning}

Polyamide nanofiltration membranes were patterned directly with silicon stamps.

Thermal embossing was used to create the patterns on the membrane surface, which causes the polymer film to deform into the nanoscale grooves of the rigid silicon stamp [33]. Therefore, the pattern produced on the membrane is a negative replica of the pattern on the silicon stamp.

Figure 2 shows an AFM image and a LEXT image of the nano-patterned silicon stamp. A unique feature of the LEXT is the ability to stitch images together. For example, a $3 \times 3$ array of $30 \mu \mathrm{m}$ $\times 30 \mu \mathrm{m}$ images can be stitched together to give a $90 \mu \mathrm{m} \times 90 \mu \mathrm{m}$ image with a higher resolution than taking one single $90 \mu \mathrm{m} \times 90 \mu \mathrm{m}$ image. LEXT imaging also is much faster than AFM, producing an image in 1-2 min when AFM would take at least 30 min to produce an image of comparable size. The LEXT can resolve features $10 \mathrm{~nm}$ in size in the $\mathrm{z}$-direction and $120 \mathrm{~nm}$ in the xy-plane. AFM gave a peak-to-peak distance of $625 \mathrm{~nm}$, which compares well to the $606 \mathrm{~nm}$ specification given by LightSmyth. The groove depth of the stamp from AFM was $231 \pm 11 \mathrm{~nm}$, which is reasonably close to the $190 \mathrm{~nm}$ specification given by LightSmyth. The LEXT image in Figure 2 shows the uniformity of the stamp across a larger area than readily accessible by AFM 
$(84 \mu \mathrm{m} \times 87 \mu \mathrm{m})$. Although, the stamp features (peaks and valleys) appear to be curved on the AFM image in Figure 2, they appear flat in $5 \mu \mathrm{m} \times 5 \mu \mathrm{m}$ images (Figure S2 in supporting information), as specified by LightSmyth.

Membranes were patterned at $45^{\circ} \mathrm{C}$ using a 20 min embossing time. Performing the thermal embossing at a lower temperature $\left(30^{\circ} \mathrm{C}\right)$ and 20 min resulted in incomplete and/or negligible patterning on the membrane. Embossing at a higher temperature $\left(65^{\circ} \mathrm{C}\right)$ for $10 \mathrm{~min}$ yielded similar groove depths as $45^{\circ} \mathrm{C}$ for $20 \mathrm{~min}$. These results imply that the ability of the membrane material to deform/flow is a key factor to pattern the membrane $[33,40]$. Also, because embossing at the two higher temperatures yielded similar results for groove depths on the membrane (vide infra), the maximum obtainable groove depth may be limited.

Figure 3 presents representative AFM images of the three types of membranes (reaction with PEGDE only, pressed with flat wafer, and patterned). AFM and LEXT gave similar results for the groove depths of the patterned membranes. The average groove depth of the various PEGDE modified, patterned membranes from AFM was $64 \pm 34 \mathrm{~nm}$ and from LEXT was $75 \pm$ $24 \mathrm{~nm}$. These groove depths are not the maximum attainable values defined by the silicon stamp. The peak-to-peak distance was consistently $625 \mathrm{~nm}$, exactly the same as the silicon stamp results from AFM. The valleys and the peaks of the patterns were always curved, which can be seen on the $20 \mu \mathrm{m} \times 20 \mu \mathrm{m}$ images shown in Figure 3 and the $5 \mu \mathrm{m} \times 5 \mu \mathrm{m}$ images provided in supporting information (Figure S3). This low resolution in the pattern replication indicates that plastic deformation, rather than viscous flow, was the mechanism for membrane patterning [33]. Figure 4 shows representative LEXT images of the patterned membranes. From the images, it is clear that the membrane surfaces had imperfections. Importantly, unmodified membrane surfaces also had similar imperfections, as can be seen in Figure S4 of the supporting information. We did 
not observe any fracturing of the polyamide surface layer, nor is there evidence from flux and salt rejection studies (vide infra) to suggest that the selective layer is fractured. Stafford and colleagues [41] quantified the strain at the onset of cracking $\varepsilon^{*}$ for nanoscale crosslinked polyamide thin films. They found $\varepsilon^{*}$ to be $14.04 \pm 4.12 \%$. In our case, the local strain defined by the height-to-pitch of the pattern is $10.6 \pm 5.6 \%$. It therefore seems reasonable that that yield of the crosslinked polyamide film could occur to form the pattern without fracturing.

\subsubsection{Chemical modification}

PEGDE was chosen to modify the surface chemistry of the membranes because it is available commercially, and its use for modification of polyamide surfaces has been shown to be relatively simple $[9,42]$. The epoxide ring opening reaction is a standard reaction between an epoxide group of PEGDE and an unreacted carboxyl group on the polyamide selective layer surface. ATR-FTIR spectroscopy was done to characterize the membrane before and after reaction with PEGDE. The PEGDE reactant in this study has an average of 8-9 ethylene oxide repeat units per molecule; therefore, changes were expected in the absorbance peaks assigned to methylene stretching in the wavenumber region from 2800 to $2900 \mathrm{~cm}^{-1}$. Figure 5 shows the spectra of membranes modified by PEGDE in the wavenumber region of interest. The increase in peak heights at approximately $2870 \mathrm{~cm}^{-1}$ and $2925 \mathrm{~cm}^{-1}$ indicate an increase in $-\mathrm{CH}_{2}$ - bonds, consistent with adding PEG onto the surface.

Additional evidence that the reaction worked would be the appearance of an absorbance peak assigned to the PEG ether group (C-O-C) in the ATR-FTIR spectrum. However, the base polyamide membrane has an absorbance peak in the same region of the PEG ether group $(\sim 1070$ $\mathrm{cm}^{-1}$ ). This absorbance corresponds to the C-C aromatic stretching of the polyamide layer [42]. 
Therefore, to determine if chemical modification was successful, we quantified changes in the absorbance peak heights of the PEG ether peak/C-C aromatic stretching peak to the C-C aromatic stretching peak of the polyamide layer at $\sim 1150 \mathrm{~cm}^{-1}$ [42], which does not change with the addition of PEG. The expectation for a successful reaction is that this absorbance ratio will increase when PEGDE is added to the membrane surface because the peak at $\sim 1070 \mathrm{~cm}^{-1}$ will increase due to the incorporation of the ether groups [42]. Figure 6 shows the dependence of the ratio of absorbance peak height at $1072 \mathrm{~cm}^{-1}$ to $1149 \mathrm{~cm}^{-1}$ on PEGDE weight percent for the reaction only membranes. As expected, the absorbance ratio increased with increasing PEGDE reaction concentration due to the presence of the PEG ether peaks on the membrane surface. This further validates a successful reaction of PEGDE onto the polyamide membrane surface.

\subsection{Membrane performance testing}

\subsubsection{Solution flux and salt rejection}

An aqueous solution of magnesium sulfate was used to challenge the membranes to ensure there was no damage to the polyamide selective layer after patterning/pressing and/or chemical modification. The manufacturer (GE) specifies a minimum magnesium sulfate rejection of $95 \%$ for the HL membrane series. Figure 7 shows the results for solution flux and salt rejection as a function of PEGDE reaction concentration for the three types of membranes. The solution flux was not affected significantly by the thermal embossing process used to pattern the membranes. Permeate flux was the same at the $68 \%$ confidence interval for each set of membranes. Paired t-tests were done to compare flux results between the unmodified membrane and pressed and patterned membranes without chemical modification. Results of these tests are given in Table $\mathrm{S} 1$ of the supporting information and show that the differences are considered to 
be not statistically significant. To further support this finding, we measured the pure water flux of a pristine membrane, applied a $15 \mathrm{wt} \%$ aqueous glycerol solution (used by manufacturers as a structure preserving agent) and dried the membrane, patterned the membrane, and then tested the pure water flux again. The flux did not change, as can be seen in Figure S5 of the supporting information. These results strongly support our claim that the patterning process does not damage the membrane.

However, the average flux values of each membrane type do decrease with increasing PEGDE concentration used to modify membranes chemically. This result is consistent with the added resistance to flow created by the addition of the PEGDE layer. One potential contributing factor to the measurement uncertainties is that samples were prepared from different membrane sheets. Membranes were purchased from a vendor (Sterlitech) in $30.5 \mathrm{~cm} \times 30.5 \mathrm{~cm}$ flat sheets. No specifications were given from where on the commercial membrane roll these sheets were cut (e.g., middle versus edge sections).

The data shown in Figure $7 \mathrm{~b}$ show no effect of thermal embossing on the salt rejection of the membrane. This result suggests that the polyamide selective layer is unimpaired by thermal embossing, consistent with the flux data. Membranes that were patterned and modified with 15 wt $\%$ PEGDE were found to have a statistical difference in rejection from the unmodified membrane (Table S1 in supporting information). For all other samples, the results of paired ttests shown in Table S1 suggest that the differences are considered to be not statistically significant, and generally consistent with the manufacturer specified $95 \%$ rejection. With the exception of the patterned, $15 \mathrm{wt} \%$ PEGDE sample, PEGDE modification does not appear to affect salt rejection. Since NF membranes rely on a combination of Donnan exclusion and size exclusion to reject salts [43], it was expected that replacement of negatively charged carboxyl 
groups by neutral PEG groups would diminish the Donnan exclusion effect of the membrane leading to lower salt rejection. However, this does not appear to be the case. The GE HL membrane has a reported molecular weight cutoff of 150-300 Da. Given the higher molecular weight of PEGDE (500 Da), it may be restricted to react with carboxyl groups on the outer membrane surface only. Therefore, unreacted carboxyl groups in the subsurface region of the selective layer may remain and contribute to salt rejection through Donnan exclusion.

\subsubsection{Sodium alginate fouling}

Sodium alginate was used as a model biopolymer to foul the membranes during crossflow filtration. Biopolymers can be a component of the conditioning film on a membrane surface prior to biofilm formation. Thus if biopolymer adsorption/attachment to the membrane is reduced/eliminated, then bacteria attachment and subsequent growth into a biofilm can be reduced/eliminated. A $90^{\circ}$ flow angle was used to see the full effect of fouling reduction caused by the patterning, as others have seen this orientation to be most effective [33, 39]. Also, a lower cross-flow velocity of $1.0 \mathrm{~m} / \mathrm{s}$ was employed to better evaluate the effect of the patterning, since foulants are more likely to accumulate on the membrane surface at lower cross-flow velocities $[44,45]$. We hypothesized that combining the membrane patterning with the chemical modification would yield membranes with better fouling resistance than those prepared by either method alone.

Figure 8 shows the flux versus time graphs for each membrane type (reaction only, pressed with flat silicon wafers, and patterned) with each PEGDE reaction concentration. Figure $8 \mathrm{~d}$ also shows a comparison between the three membrane types (reaction only, pressed, and patterned) with no chemical modification ( $0 \mathrm{wt} \%)$. Figure $\mathrm{S} 6$ of supporting information 
summarizes the average flux reduction for all membranes based on the integrated flux over a $2 \mathrm{~h}$ period. The approximate initial starting flux for each membrane tested was $120 \mathrm{~L} / \mathrm{m}^{2} / \mathrm{h}$ to enable direct comparison of results. Figures $8 \mathrm{a}$ and S6 show that the unmodified membrane (0 wt $\%)$ had the largest decrease in average flux values from $120 \mathrm{~L} / \mathrm{m}^{2} / \mathrm{h}$ to $78 \mathrm{~L} / \mathrm{m}^{2} / \mathrm{h}$. The effect of chemical modification alone had a positive impact on the resistance to fouling by reducing the flux decline. In both cases (5 and $15 \mathrm{wt} \%$ ), the average flux declined from $121 \mathrm{~L} / \mathrm{m}^{2} / \mathrm{h}$ to about 110 $\mathrm{L} / \mathrm{m}^{2} / \mathrm{h}$. Statistically there was no difference in flux decline between membranes modified by the 5 and $15 \mathrm{wt} \%$ PEGDE solutions. The positive impact of the PEGDE chemical modification is attributed to the strong hydration layer that forms around PEG, as well as the increase in hydrophilicity of the membranes. Figure S7 shows the data for water contact angle on the reaction only membranes. The data show a decrease in the average water contact angle as the PEGDE reaction concentration increases, indicating an increase in membrane hydrophilicity with PEGDE addition. These results indicate that chemical modification alone is an effective method at reducing fouling, but there is still opportunity for improvement even with this simple model foulant solution.

Figures $8 \mathrm{~b}$ and $\mathrm{S} 6$ show the results for the membranes pressed by flat silicon wafers and modified with PEGDE. The purpose of these experiments was to see if thermal compression of the membranes made a meaningful contribution to fouling reduction. As can be seen in Figure $8 \mathrm{~d}$, the unmodified, pressed membrane $(0 \mathrm{wt} \%)$ had a significant reduction in fouling rate from $113 \mathrm{~L} / \mathrm{m}^{2} / \mathrm{h}$ to $100 \mathrm{~L} / \mathrm{m}^{2} / \mathrm{h}$ compared to the unmodified, non-pressed membrane. The cause for this result can be attributed to the reduction in membrane surface roughness as a result of pressing $[12,38,46]$. Figure 9 shows the results obtained from the LEXT for surface roughness on a $0.004 \mathrm{~mm}^{2}$ membrane area using a 50x objective with a numerical aperture of 0.95 . The 
pressed membranes showed a significant decrease in the RMS height (aka which indicates roughness) of the surface compared to the reaction only membranes. The surface roughness data indicate that membranes were flattened by pressing, resulting in a membrane that has an increased fouling resistance. Statistically, there was no difference among the pressed membranes (unmodified and PEGDE modified) in terms of membrane fouling (Figure S6). This result indicates that there may be a long-term benefit of reducing membrane surface roughness via compression on membrane fouling resistance.

Figure $8 \mathrm{c}$ shows the results of membrane fouling with alginate on the patterned membranes. The surface patterning alone had a similar effect to the pressing alone, having a flux decline from $117 \mathrm{~L} / \mathrm{m}^{2} / \mathrm{h}$ to $103 \mathrm{~L} / \mathrm{m}^{2} / \mathrm{h}$, as can be seen in Figure 8d. Figure 9 shows that the membrane roughness for the patterned membranes was higher than the pressed membranes, which is not surprising since patterning introduces ordered "roughness" to the surface. Despite this higher roughness than pressed membranes, the patterned membranes performed as well or better during fouling challenges. On average, the patterned membranes had slightly lower roughness than non-pressed membranes. While there may have been some benefit from reducing the membrane surface roughness, the introduction of ordered roughness on the membrane surface appears to have the added benefit of disrupting the hydrodynamic boundary layer during flow over the membrane.

Figure $8 \mathrm{c}$ also shows the added benefit of combining patterning with changes to the surface chemistry of the membrane. Statistically, there was no difference between patterned and pressed membranes in terms of membrane fouling; however, there does appear to be a slight difference in average membrane fluxes, with patterned membranes showing less average flux decline than pressed samples (Figure S6). Patterned membranes that were modified using 15 
wt\% PEGDE maintained a constant flux of approximately $120 \mathrm{LMH}$ during the $2 \mathrm{~h}$ test. A patterned membrane modified using $15 \mathrm{wt} \%$ PEGDE was also tested for $7 \mathrm{~h}$ with an initial flux of $90 \mathrm{LMH}$ and saw essentially no flux decline as well. These data are presented in Figure S8 in supporting information. These results suggest that combining nanopatterning with chemical modification on a membrane surface can lead to a membrane with lower propensity to foul than by using either method alone.

\section{Conclusions}

A method was developed for combining physical nanopatterning and chemical modification of a polyamide thin-film composite nanofiltration membrane surface to reduce membrane fouling by alginate without hindering membrane flux or salt rejection. The patterned membrane surface consisted of a line and groove topography that was applied to the membrane by a thermal embossing process. Chemical modification was done using a PEG-based coating. Whereas the unmodified membranes had an average flux reduction of $22 \%$ based on the integrated flux over the $2 \mathrm{~h}$ test period, the chemically modified, patterned membranes had 0-8\% flux reduction depending on the degree of chemical modification. The enhanced fouling resistance of the chemically modified, patterned membranes was attributed to increases in surface hydrophilicity and water hydration, as well as the improved flow dynamics across the membrane surface caused by the patterns. Ongoing work is exploring a variety of nanopatterns and alternate chemical modification strategies, as PEG has a tendency to degrade when exposed to cleaning solutions.

\section{Acknowledgements}


SW was supported by a National Science Foundation Graduate Research Fellowship under Award DGE-1246875. We wish to acknowledge the National Science Foundation for financial support under NSF award CBET-1534304. Any opinion, findings, and conclusions or recommendations expressed in this material are those of the authors(s) and do not necessarily reflect the views of the NSF. We thank Clemson University for funding through the Tiger Grant Award program. We thank Dr. Terri Bruce and Ms. Rhonda Powell of the Clemson Light Imaging Facility for help and discussions with LEXT measurements. We thank the Clemson Machining and Technical Services for fabrication of the custom cross-flow cell. We thank $\mathrm{Na} \mathrm{Li}$ for her contribution to discussions on this work.

\section{Appendix A. Supporting Information}

Supplementary data associated with this article can be found in the online version.

\section{References}

[1] O. Habimana, A. Semião, E. Casey, The role of cell-surface interactions in bacterial initial adhesion and consequent biofilm formation on nanofiltration/reverse osmosis membranes, Journal of Membrane Science, 454 (2014) 82-96.

[2] T. Nguyen, F.A. Roddick, L. Fan, Biofouling of water treatment membranes: a review of the underlying causes, monitoring techniques and control measures, Membranes, 2 (2012) 804-840.

[3] M. Herzberg, M. Elimelech, Biofouling of reverse osmosis membranes: role of biofilm-enhanced osmotic pressure, Journal of Membrane Science, 295 (2007) 11-20.

[4] W. Guo, H.-H. Ngo, J. Li, A mini-review on membrane fouling, Bioresource technology, 122 (2012) 2734.

[5] D. Rana, T. Matsuura, Surface modifications for antifouling membranes, Chemical reviews, 110 (2010) 2448-2471.

[6] G.-d. Kang, Y.-m. Cao, Development of antifouling reverse osmosis membranes for water treatment: a review, Water research, 46 (2012) 584-600.

[7] E. Ostuni, R.G. Chapman, R.E. Holmlin, S. Takayama, G.M. Whitesides, A survey of structure-property relationships of surfaces that resist the adsorption of protein, Langmuir, 17 (2001) 5605-5620.

[8] G.-d. Kang, Z.-n. Liu, H.-j. Yu, Y.-m. Cao, Enhancing antifouling property of commercial polyamide reverse osmosis membrane by surface coating using a brush-like polymer containing poly (ethylene glycol) chains, Desalination and Water Treatment, 37 (2012) 139-145. 
[9] E.M. Van Wagner, A.C. Sagle, M.M. Sharma, Y.-H. La, B.D. Freeman, Surface modification of commercial polyamide desalination membranes using poly (ethylene glycol) diglycidyl ether to enhance membrane fouling resistance, Journal of Membrane Science, 367 (2011) 273-287.

[10] M. Hadidi, A.L. Zydney, Fouling behavior of zwitterionic membranes: Impact of electrostatic and hydrophobic interactions, Journal of Membrane Science, 452 (2014) 97-103.

[11] Y.-C. Chiang, Y. Chang, C.-J. Chuang, R.-C. Ruaan, A facile zwitterionization in the interfacial modification of low bio-fouling nanofiltration membranes, Journal of Membrane Science, 389 (2012) 7682.

[12] R. Yang, J. Xu, G. Ozaydin-Ince, S.Y. Wong, K.K. Gleason, Surface-tethered zwitterionic ultrathin antifouling coatings on reverse osmosis membranes by initiated chemical vapor deposition, Chemistry of Materials, 23 (2011) 1263-1272.

[13] F. Razi, I. Sawada, Y. Ohmukai, T. Maruyama, H. Matsuyama, The improvement of antibiofouling efficiency of polyethersulfone membrane by functionalization with zwitterionic monomers, Journal of Membrane Science, 401 (2012) 292-299.

[14] J.C. Tiller, C.-J. Liao, K. Lewis, A.M. Klibanov, Designing surfaces that kill bacteria on contact, Proceedings of the National Academy of Sciences, 98 (2001) 5981-5985.

[15] Y.-F. Yang, H.-Q. Hu, Y. Li, L.-S. Wan, Z.-K. Xu, Membrane surface with antibacterial property by grafting polycation, Journal of Membrane Science, 376 (2011) 132-141.

[16] F.o. Perreault, M.E. Tousley, M. Elimelech, Thin-film composite polyamide membranes functionalized with biocidal graphene oxide nanosheets, Environmental Science \& Technology Letters, 1 (2013) 71-76.

[17] A. Tiraferri, C.D. Vecitis, M. Elimelech, Covalent binding of single-walled carbon nanotubes to polyamide membranes for antimicrobial surface properties, ACS applied materials \& interfaces, 3 (2011) 2869-2877.

[18] W.-R. Li, X.-B. Xie, Q.-S. Shi, H.-Y. Zeng, O.-Y. You-Sheng, Y.-B. Chen, Antibacterial activity and mechanism of silver nanoparticles on Escherichia coli, Applied microbiology and biotechnology, 85 (2010) 1115-1122.

[19] J. Yin, Y. Yang, Z. Hu, B. Deng, Attachment of silver nanoparticles (AgNPs) onto thin-film composite (TFC) membranes through covalent bonding to reduce membrane biofouling, Journal of Membrane Science, 441 (2013) 73-82.

[20] M.L. Carman, T.G. Estes, A.W. Feinberg, J.F. Schumacher, W. Wilkerson, L.H. Wilson, M.E. Callow, J.A. Callow, A.B. Brennan, Engineered antifouling microtopographies-correlating wettability with cell attachment, Biofouling, 22 (2006) 11-21.

[21] R.M. May, M.G. Hoffman, M.J. Sogo, A.E. Parker, G.A. O'Toole, A.B. Brennan, S.T. Reddy, Micropatterned surfaces reduce bacterial colonization and biofilm formation in vitro: Potential for enhancing endotracheal tube designs, Clinical and translational medicine, 3 (2014) 1-9.

[22] R. Vasudevan, A.J. Kennedy, M. Merritt, F.H. Crocker, R.H. Baney, Microscale patterned surfaces reduce bacterial fouling-microscopic and theoretical analysis, Colloids and Surfaces B: Biointerfaces, 117 (2014) 225-232.

[23] I.S. Ngene, R.G. Lammertink, M. Wessling, W.G. Van der Meer, Particle deposition and biofilm formation on microstructured membranes, Journal of Membrane Science, 364 (2010) 43-51.

[24] J.A. Kharraz, M. Bilad, H.A. Arafat, Simple and effective corrugation of PVDF membranes for enhanced MBR performance, Journal of Membrane Science, 475 (2015) 91-100.

[25] P. Culfaz, M. Haddad, M. Wessling, R. Lammertink, Fouling behavior of microstructured hollow fibers in cross-flow filtrations: Critical flux determination and direct visual observation of particle deposition, Journal of Membrane Science, 372 (2011) 210-218. 
[26] M. Hashino, T. Katagiri, N. Kubota, Y. Ohmukai, T. Maruyama, H. Matsuyama, Effect of surface roughness of hollow fiber membranes with gear-shaped structure on membrane fouling by sodium alginate, Journal of Membrane Science, 366 (2011) 389-397.

[27] I. Kim, D.-C. Choi, J. Lee, H.-R. Chae, J.H. Jang, C.-H. Lee, P.-K. Park, Y.-J. Won, Preparation and application of patterned hollow-fiber membranes to membrane bioreactor for wastewater treatment, Journal of Membrane Science, 490 (2015) 190-196.

[28] Y. Gençal, E. Durmaz, P. Çulfaz-Emecen, Preparation of patterned microfiltration membranes and their performance in crossflow yeast filtration, Journal of Membrane Science, 476 (2015) 224-233.

[29] Y.-J. Won, J. Lee, D.-C. Choi, H.R. Chae, I. Kim, C.-H. Lee, I.-C. Kim, Preparation and application of patterned membranes for wastewater treatment, Environmental science \& technology, 46 (2012) 11021-11027.

[30] Y.-J. Won, D.-C. Choi, J.H. Jang, J.-W. Lee, H.R. Chae, I. Kim, K.H. Ahn, C.-H. Lee, I.-C. Kim, Factors affecting pattern fidelity and performance of a patterned membrane, Journal of Membrane Science, 462 (2014) 1-8.

[31] S.H. Maruf, M. Rickman, L. Wang, J. Mersch IV, A.R. Greenberg, J. Pellegrino, Y. Ding, Influence of sub-micron surface patterns on the deposition of model proteins during active filtration, Journal of Membrane Science, 444 (2013) 420-428.

[32] S.H. Maruf, A.R. Greenberg, J. Pellegrino, Y. Ding, Critical flux of surface-patterned ultrafiltration membranes during cross-flow filtration of colloidal particles, Journal of Membrane Science, 471 (2014) 65-71.

[33] S.H. Maruf, L. Wang, A.R. Greenberg, J. Pellegrino, Y. Ding, Use of nanoimprinted surface patterns to mitigate colloidal deposition on ultrafiltration membranes, Journal of Membrane Science, 428 (2013) 598-607.

[34] S.H. Maruf, A.R. Greenberg, J. Pellegrino, Y. Ding, Fabrication and characterization of a surfacepatterned thin film composite membrane, Journal of Membrane Science, 452 (2014) 11-19.

[35] M. Hashino, T. Katagiri, N. Kubota, Y. Ohmukai, T. Maruyama, H. Matsuyama, Effect of membrane surface morphology on membrane fouling with sodium alginate, Journal of Membrane Science, 366 (2011) 258-265.

[36] F. Wan, X. Pei, B. Yu, Q. Ye, F. Zhou, Q. Xue, Grafting polymer brushes on biomimetic structural surfaces for anti-algae fouling and foul release, ACS applied materials \& interfaces, 4 (2012) 4557-4565.

[37] C.Y. Tang, Y.-N. Kwon, J.O. Leckie, Effect of membrane chemistry and coating layer on physiochemical properties of thin film composite polyamide RO and NF membranes: I. FTIR and XPS characterization of polyamide and coating layer chemistry, Desalination, 242 (2009) 149-167. [38] Q. Li, Z. Xu, I. Pinnau, Fouling of reverse osmosis membranes by biopolymers in wastewater secondary effluent: Role of membrane surface properties and initial permeate flux, Journal of Membrane Science, 290 (2007) 173-181.

[39] R.J. Gohari, W.J. Lau, T. Matsuura, A.F. Ismail, Effect of surface pattern formation on membrane fouling and its control in phase inversion process, Journal of Membrane Science, 446 (2013) 326-331. [40] S.H. Maruf, Z. Li, J.A. Yoshimura, J. Xiao, A.R. Greenberg, Y. Ding, Influence of nanoimprint lithography on membrane structure and performance, Polymer, 69 (2015) 129-137.

[41] J.Y. Chung, J.-H. Lee, K.L. Beers, C.M. Stafford, Stiffness, strength, and ductility of nanoscale thin films and

membranes: a combined wrinkling-cracking methodology, Nano Lett, 11 (2011) 3361-3365.

[42] S.R.-V. Castrillón, X. Lu, D.L. Shaffer, M. Elimelech, Amine enrichment and poly (ethylene glycol)(PEG) surface modification of thin-film composite forward osmosis membranes for organic fouling control, Journal of Membrane Science, 450 (2014) 331-339. 
[43] A. Szymczyk, Y. Lanteri, P. Fievet, Modelling the transport of asymmetric electrolytes through nanofiltration membranes, Desalination, 245 (2009) 396-407.

[44] H. Choi, K. Zhang, D.D. Dionysiou, D.B. Oerther, G.A. Sorial, Influence of cross-flow velocity on membrane performance during filtration of biological suspension, Journal of membrane science, 248 (2005) 189-199.

[45] S. Suwarno, X. Chen, T. Chong, D. McDougald, Y. Cohen, S. Rice, A. Fane, Biofouling in reverse osmosis processes: The roles of flux, crossflow velocity and concentration polarization in biofilm development, Journal of Membrane Science, 467 (2014) 116-125.

[46] J. Wei, C. Qiu, Y.-N. Wang, R. Wang, C.Y. Tang, Comparison of NF-like and RO-like thin film composite osmotically-driven membranes-implications for membrane selection and process optimization, Journal of Membrane Science, 427 (2013) 460-471. 


\section{Figures}

Step 1. Pattern membrane with silicon stamp

Step 2. Apply chemical coating
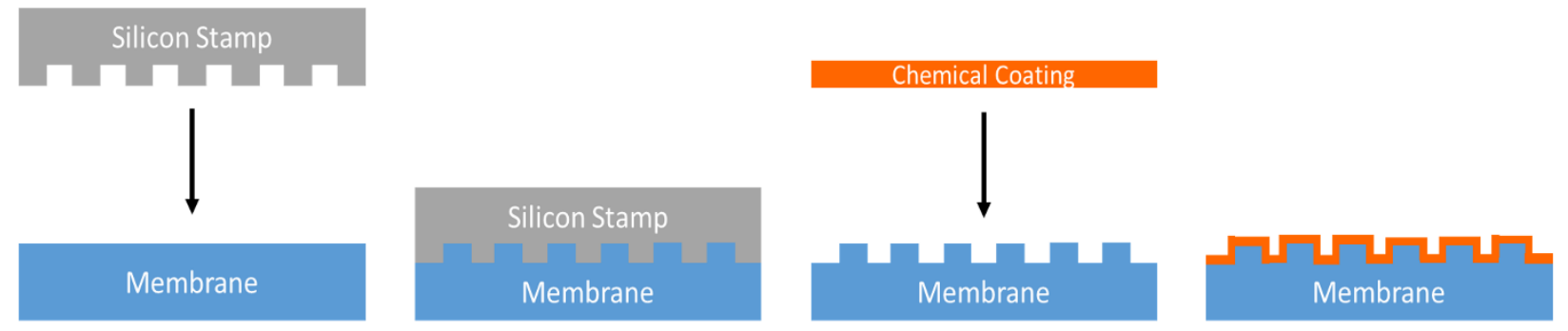

Figure 1. Methodology of combining chemical coating and physical patterning on a membrane surface by deformation (i.e., embossing) of the membrane substrate. The chemical coating is a poly(ethylene glycol) diglycidyl ether aqueous solution. 

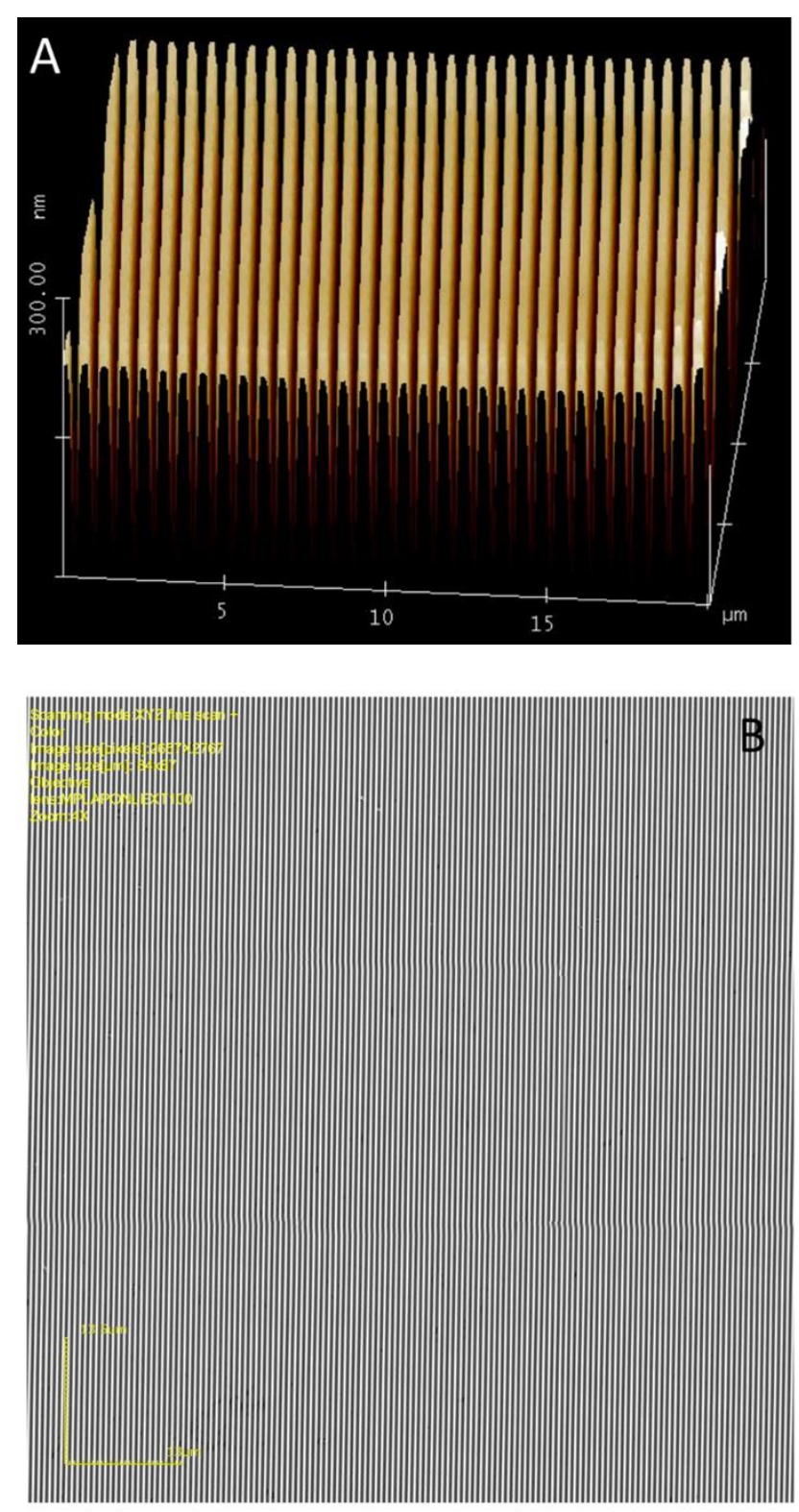

Figure 2. Silicon stamp images produced by (A) AFM and (B) LEXT. The AFM image is $20 \mu \mathrm{m}$ $\times 20 \mu \mathrm{m} \times 300 \mathrm{~nm}$ and gives an average groove depth of $231 \pm 11 \mathrm{~nm}$ and a period of $625 \mathrm{~nm}$.

The LEXT image is an $84 \mu \mathrm{m} \times 87 \mu \mathrm{m}$ image produced from stitching images together from the 100x objective with a 4x optical zoom. The scale bar in the LEXT image is $13.5 \mu \mathrm{m}$ (y-direction) $\times 13 \mu \mathrm{m}$ (x-direction). 

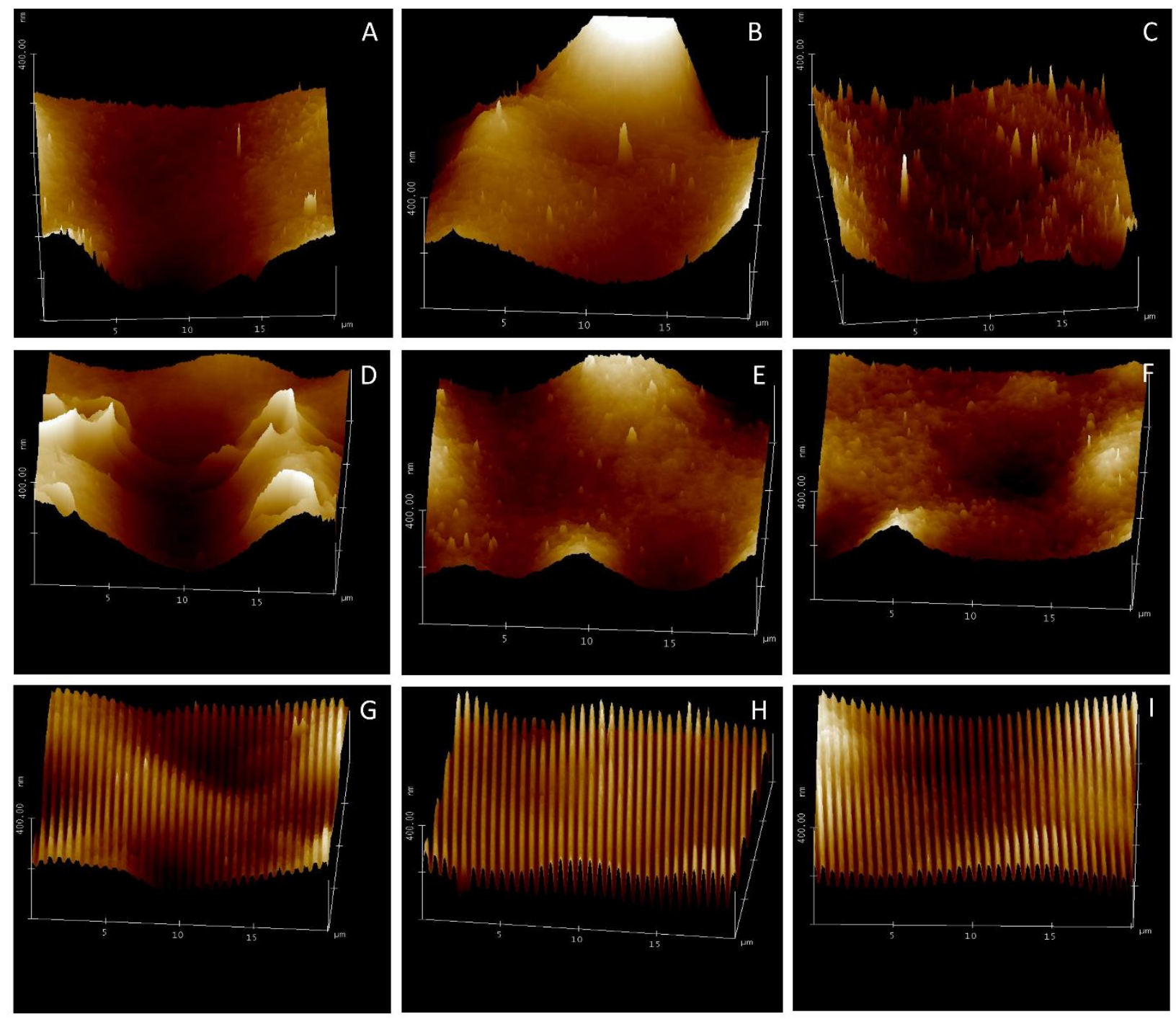

Figure 3. AFM images of the 3 types of membranes modified with varying concentrations of aqueous PEGDE solutions. Reaction with PEGDE only: $0 \mathrm{wt} \%$ (A, control), $5 \mathrm{wt} \%$ (B), $15 \mathrm{wt} \%$ (C); pressed with flat silicon wafer: $0 \mathrm{wt} \%$ (D), $5 \mathrm{wt} \%$ (E), $15 \mathrm{wt} \%$ (F); and patterned: $0 \mathrm{wt} \%$ (G), $5 \mathrm{wt} \%(\mathrm{H}), 15 \mathrm{wt} \%$ (I). The common scale is $20 \mu \mathrm{m} \times 20 \mu \mathrm{m} \times 400 \mathrm{~nm}$. 

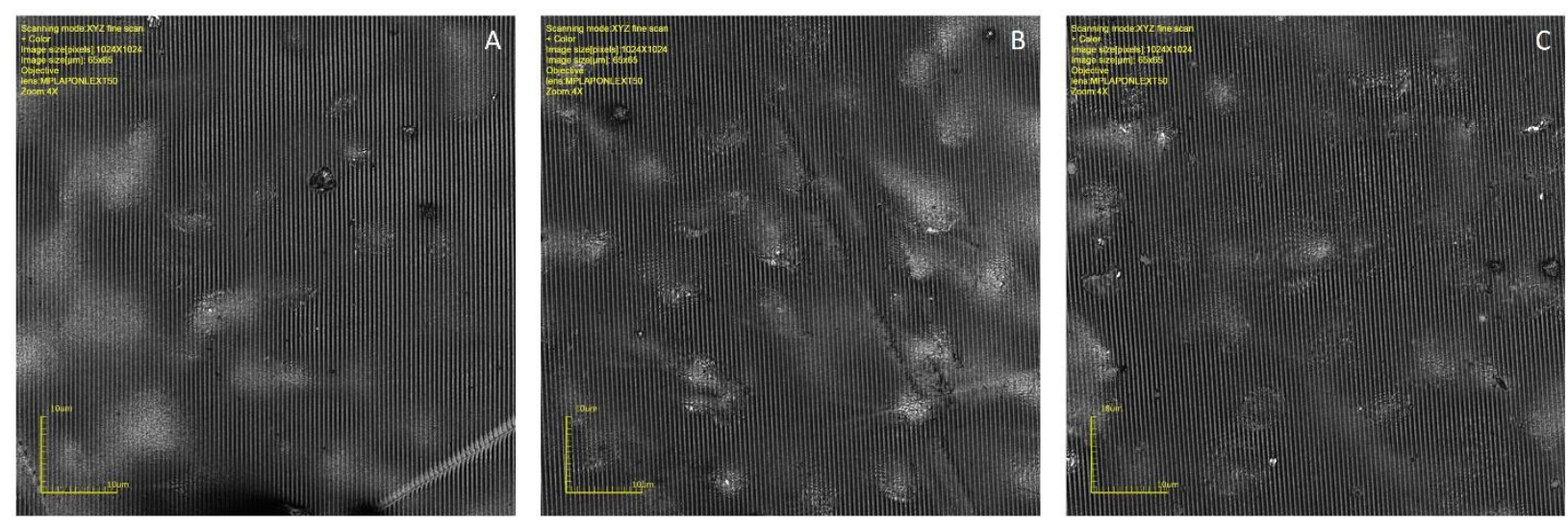

Figure 4. LEXT images of patterned membranes modified with varying concentrations of aqueous PEGDE solutions: $0 \mathrm{wt} \%$ (A), $5 \mathrm{wt} \%$ (B), $15 \mathrm{wt} \%$ (C). Common image scale is $65 \mu \mathrm{m}$ $\times 65 \mu \mathrm{m}$. The images were produced from the 50x objective with a 4x optical zoom. The scale bar in each image is $10 \mu \mathrm{m}(\mathrm{y}$-direction $) \times 10 \mu \mathrm{m}(\mathrm{x}$-direction $)$. 


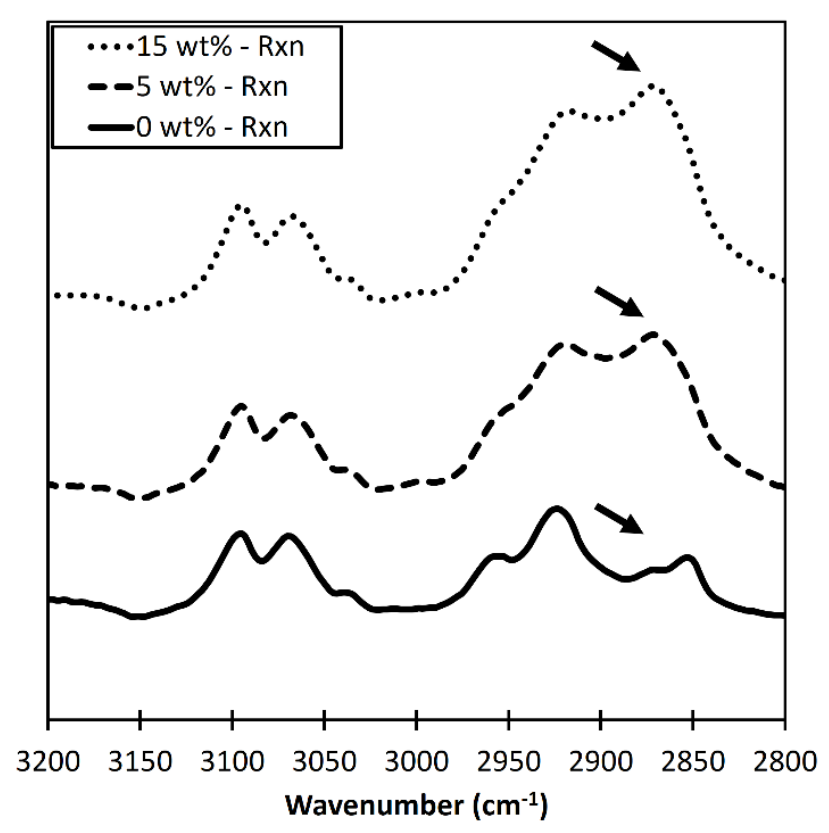

Figure 5. ATR-FTIR spectra at a common scale for membranes modified by PEGDE only.

Labels with percentages correspond to the varying concentrations of aqueous PEGDE reaction solutions used. 


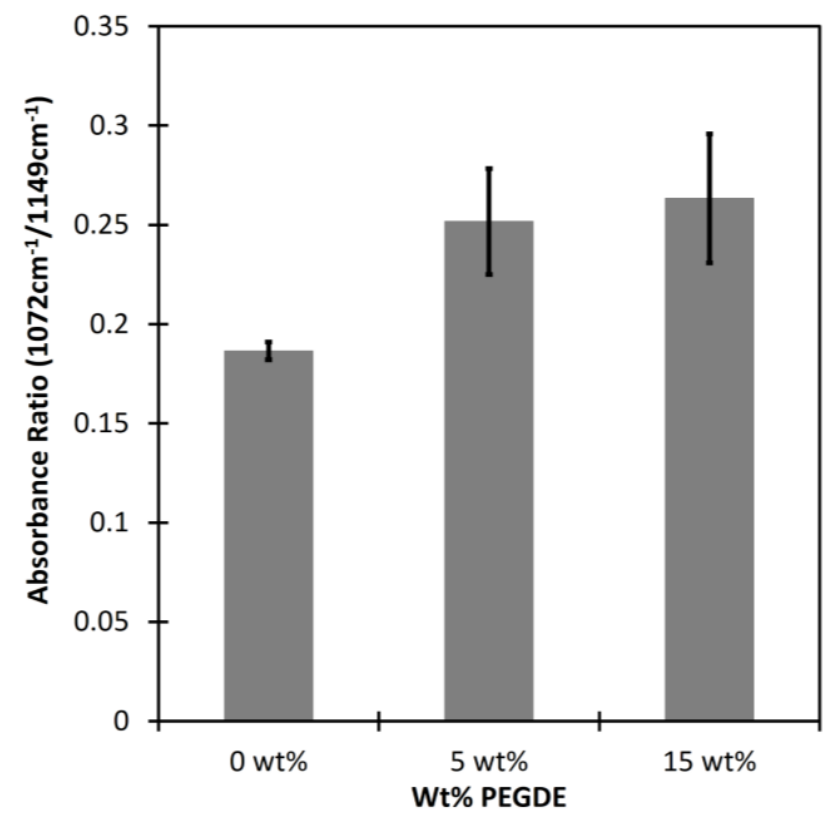

Figure 6. Absorbance ratio of the $1072 \mathrm{~cm}^{-1}$ peak to the $1149 \mathrm{~cm}^{-1}$ peak from ATR-FTIR data for membranes modified by PEGDE only. The $\mathrm{x}$-axis corresponds to the concentration of aqueous PEGDE reaction solutions used for chemical modification. The peak at $1072 \mathrm{~cm}^{-1}$ corresponds to the $\mathrm{C}-\mathrm{O}$ stretching of the PEG ether group and the $\mathrm{C}-\mathrm{C}$ aromatic stretching of the polyamide layer. The peak at $1149 \mathrm{~cm}^{-1}$ corresponds to the $\mathrm{C}-\mathrm{C}$ aromatic stretching of the polyamide layer. The error bars represent one standard deviation from at least 3 different membrane samples. 

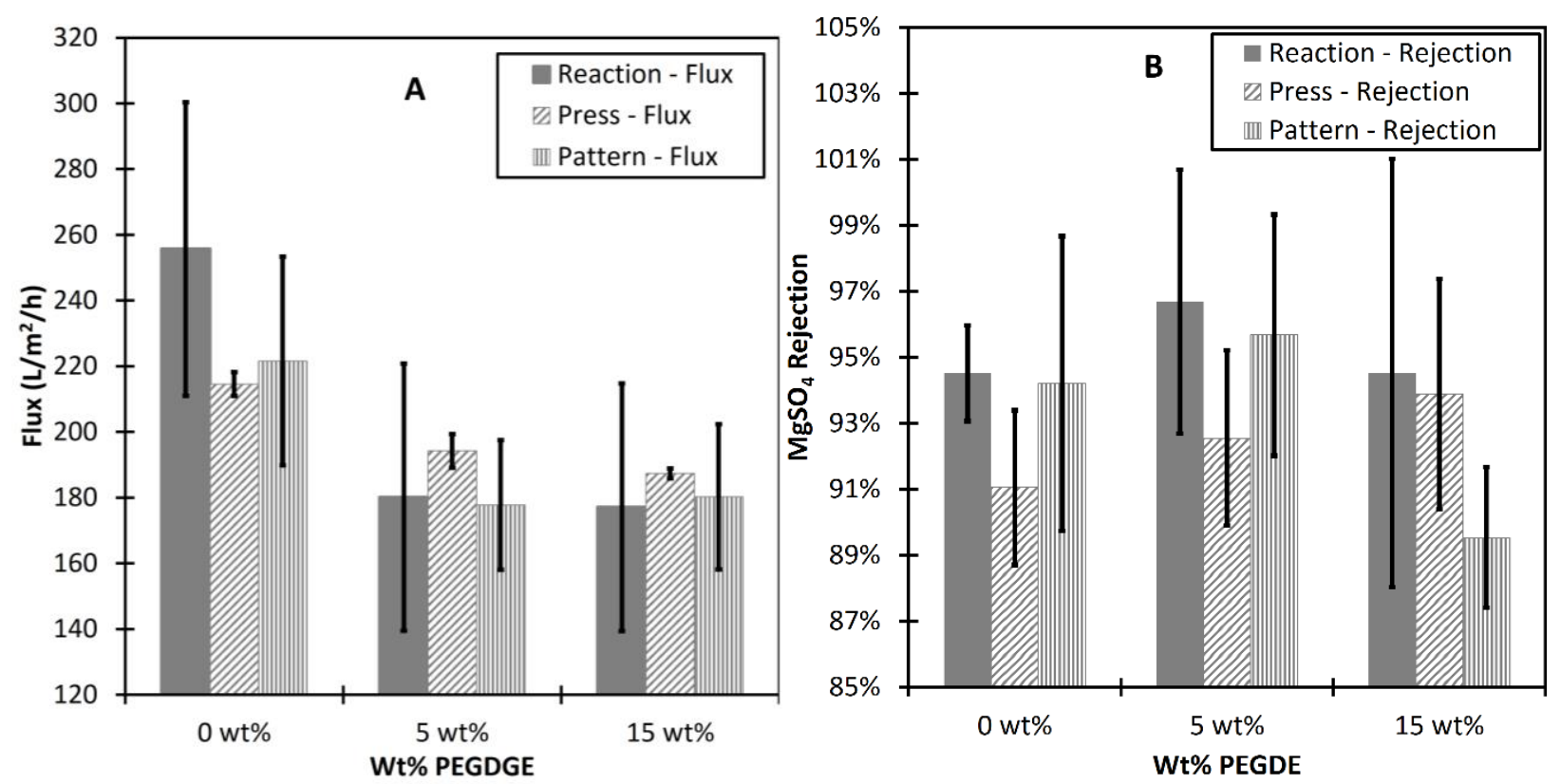

Figure 7. Solution flux [LMH] (A) and magnesium sulfate rejection [\%] (B) versus weight percent of aqueous PEGDE solutions for the three types of membranes (reaction only, pressed with flat silicon wafers, and patterned). The feed was a 2000 ppm magnesium sulfate solution. The pressure applied to the feed side was $8.6 \mathrm{barg}$, the solution temperature was $22-23^{\circ} \mathrm{C}$, the cross flow velocity was $3.0 \pm 0.2 \mathrm{~m} / \mathrm{s}$, and the membrane area tested was $5.6 \mathrm{~cm}^{2}$, with patterning on $62 \%$ of this area. The flow angle used between the solution flow and the membrane patterns was $0^{\circ}$ (parallel). The error bars represent one standard deviation among 3 membrane samples. 

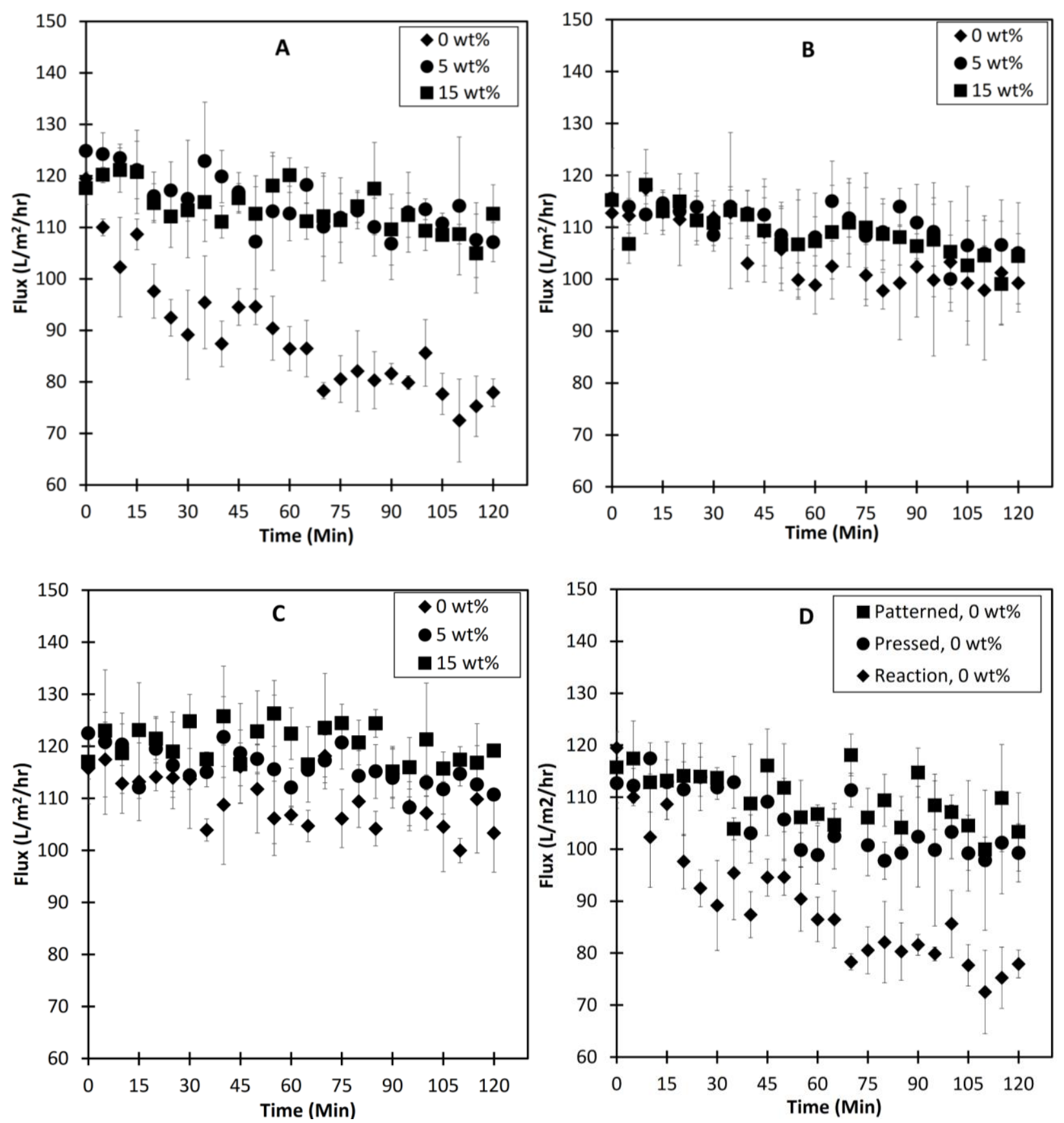

Figure 8. Sodium alginate fouling tests for membranes modified by PEGDE reaction only (A), membranes pressed with a flat silicon wafer (B), patterned membranes (C), and each membrane type with no chemical modification (D). A, B, and C includes data for membranes modified with the aqueous PEGDE solutions (0, 5, and $15 \mathrm{wt} \%$ ). The feed solution comprised $30 \mathrm{mg} / \mathrm{L}$ sodium alginate, $10 \mathrm{mM} \mathrm{NaCl}$, and $1 \mathrm{mM} \mathrm{CaCl}$. The temperature was $22-23^{\circ} \mathrm{C}$, the cross-flow velocity was $1.0 \pm 0.1 \mathrm{~m} / \mathrm{s}$, and tested membrane area was $5.6 \mathrm{~cm}^{2}$, with patterning on $68 \%$ of this area. The approximate initial starting flux was $120 \mathrm{LMH}$ for all samples. The flow angle used between the solution flow and the membrane patterns was $90^{\circ}$ (perpendicular). The error bars represent one standard deviation among 3 membrane samples. 


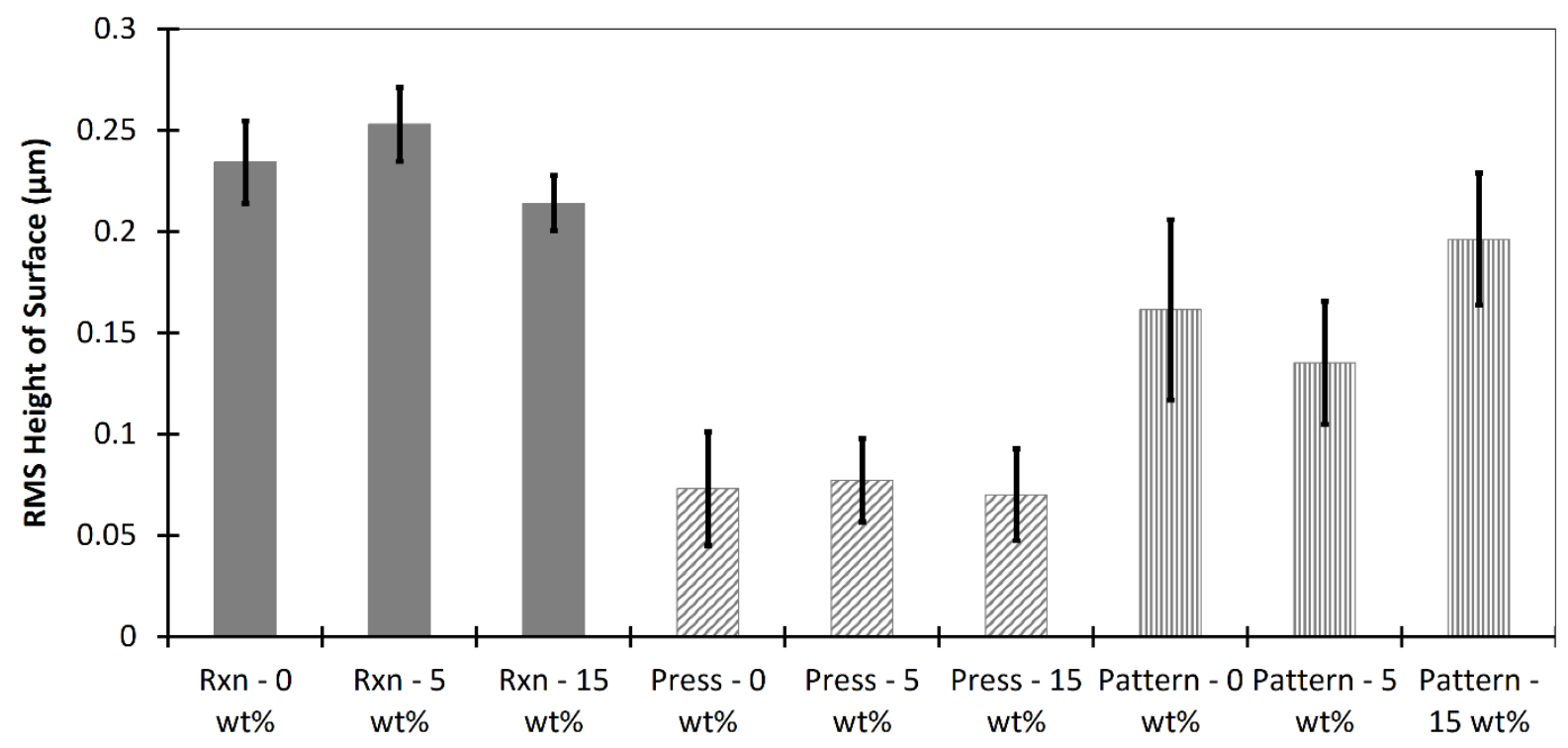

Figure 9. RMS height of the membrane surfaces. The results were obtained using the LEXT with the 50x objective at a 4x optical zoom. The membrane area studied per image was 0.004 $\mathrm{mm}^{2}$. The error bars represent one standard deviation among at least 3 membrane samples. 
